\title{
A Towering Critique of the Ambience of Social Welfare, Social Work and the Social Development Paradigm-An African Analysis
}

\author{
Ani Casimir ${ }^{1}$, Ejiofor Samuel ${ }^{2}$ \\ ${ }^{1}$ Department of Philosophy, Institute of African Studies, University of Nigeria, Nsukka, Nigeria \\ ${ }^{2}$ Department of Social Work, University of Nigeria, Nsukka, Nigeria \\ Email: cepperngo@yahoo.com, ejorsamchi@yahoo.com
}

Received 10 January 2015; accepted 9 June 2015; published 12 June 2015

Copyright (C) 2015 by authors and Scientific Research Publishing Inc.

This work is licensed under the Creative Commons Attribution International License (CC BY). http://creativecommons.org/licenses/by/4.0/

(c) $)$ (i) 0 pen Access

\begin{abstract}
What should be the African social worker in the modern world. The African social worker has discovered that most clinical and other modern social work practices are Euro-centric. And only reflect only European values. He knows that African communal social work practices existed in an ethnocentric environment that encourages an African-centred world view. How this African centred world view wouyld help him to define a new social work values with a paradigmatic shift to his roles as a profession is a challenge to both social philosophy and its social work concentrates. Therefore this article raises serious concerns about the ethnocentric nature of existing paradigms within the social sciences that form the basis for social work theory and practice with implications for modern social work in Africa. In addition, it highlights the theoretical deficits within existing social work models that do not reflect the worldviews of diverse cultural communities in modern world. Can existing social work models continue to express ethnocentric value systems as the universal way to explain human behaviour in the light of growing demands for pluralism not only between groups but also between epistemologies and worldviews? The authors of the article, writing from the perspective of the new African social science, argues for an alternative paradigm that is grounded in the cultural and historical reality of the African communal experience.
\end{abstract}

\section{Keywords}

Social Philosophy, Ambience, Social Work, Social Welfare, African World View, Communalism and Social Development

\section{Introduction-The Values and Basic Concepts of Social Work and Social Welfare}

Social welfare is an adjunct of social philosophy and subtiantial part of the discipline of social work. Social philosophy are those social and political values, ethos and mores that define the purpose and objectives of the social

How to cite this paper: Casimir, A., \& Samuel, E. (2015). A Towering Critique of the Ambience of Social Welfare, Social Work and the Social Development Paradigm-An African Analysis. Open Journal of Political Science, 5, 236-246. 
good of the community, the society or the state and its citizens, social work could be defined by an appeal to a global authority. We can depend on a working definition of social work was approved by the IFSW General Meeting and the IASSW General Assembly in July 2014:

"Social work is a practice-based profession and an academic discipline that promotes social change and development, social cohesion, and the empowerment and liberation of people. Principles of social justice, human rights, collective responsibility and respect for diversities are central to social work. Underpinned by theories of social work, social sciences, humanities and indigenous knowledge, social work engages people and structures to address life challenges and enhance wellbeing. The above definition may be amplified at national and/or regional levels".

Mekada (2013) in his "The African-Centred Worldview: Developing a Paradigm for Social Work", made a very possible argument about the need for a plural source of values that could reflect the diverse cultural of mankind to inform social philosophy and social work. His views point to the fact that social work is about alleviation of humanity's social problems and embarking upon social problems of a particular people with particular cultural backgrounds thus:

A broad base of information and discussion of the African-centred worldview and the development of Africancentred perspectives in social work is explored. African-centred perspectives in social work challenge the profession to express its core principles of equality, social justice and self-determination in embracing alternative worldviews and paradigms as legitimate and valid bases for social work theory and practice.

A philosophical tour of the conceptual world of social work and welfare would be apposite and would give a value-based exposition why African centred world view would be needful in redefining the value parameters of social work practice in Africa. Several definitions of social welfare had been given by the state and scholars of social philosophy and social work practices. Dolgoff \& Feldstein (1980) Understanding Social Welfare (p. 91): "In its narrowest sense, social welfare includes those nonprofit functions of society, public or voluntary, which are clearly aimed at alleviating distress and poverty or at ameliorating the conditions of the casualties of society." On their part Dolgoff, Feldstein, \& Stolnik (1997) Understanding Social Welfare, 4th ed. p. 5: "All social interventions intended to enhance or maintain the social functioning of human beings." Waxing organizational in conceptual definition, the National Association of Social Workers, Encyclopedia of Social Work Vol. II, 1971, p. 1446: "Social welfare generally denotes the full range of organized activities of voluntary and governmental agencies that seek to prevent, alleviate, or contribute to the solution of recognized social problems, or to improve the well-being of individuals, groups, or communities". The United Nations takes the philosophical cake as the chief social care and welfare officer of the world as a standard and best practices dispenser. In 1967 the United Nations defined social welfare as:

"Social welfare as an organized function is regarded as a body of activities designed to enable individuals, families, groups and communities to cope with the social problems of changing conditions. But in addition to and extending beyond the range of its responsibilities for specific services, social welfare has a further function within the broad area of a country's social development. In this larger sense, social welfare should play a major role in contributing to the effective mobilization and deployment of human and material resources of the country to deal successfully with the social requirements of change, thereby participating in nation-building."

A Hong Kong Government 1965 White Paper, released after the study of social and social welfare concerns of its underprivileged citizens under its care, defined social welfare very broadly in the following tripartite form:

Social welfare services, in common with education, medical, housing and other parallel services, form a part of the social services which most developed communities have come to require and expect ... Social welfare services are required by those who are not capable without help and support of standing on their own feet as fully independent or "self-directing" members of the community. "Used in its broadest sense the term "social welfare" can embrace all efforts aimed at improving health, education, employment, housing, recreational and cultural services for the community at large. However, for the purpose of the White Paper, "social welfare" will be used in a narrower sense as the range of services provided by Social Welfare Department and the voluntary welfare sector" (1979).

From the above we can intuit that social welfare embraces laws, programmes, benefits and services which address social needs accepted as essential to the well-being of a society. So, social work is about social welfare as it focuses on personal and social problems, seeking for sustainable solutions. This explains why the Hong Kong Government "The Five Year Plan for Social Welfare Development in Hong Kong-Review 1998" by Social Welfare Department (p. 3): 
"Social welfare (in HK) embraces laws, programmes, benefits and services which address social needs accepted as essential to the well-being of a society. It focuses on personal and social problems, both existing and potential. It also plays an important developmental role by providing an organized system of services and institutions which are designed to aid individuals and groups to achieve satisfying roles in life and personal relationships which permit them to develop their full capacities and to promote their well-being in harmony with the needs and aspirations of their families and the community."

\section{Nature of Social Welfare: A Philosophical Exposition}

Social welfare is of the five systems of social services in modern industrial societies. Philosophically, social welfare is conceived in a broad sense, which is also called "social service" which includes education, medical \& health, housing, income maintenance, and personal welfare. This is why "social welfare" if defined in a narrow sense refers to "personal welfare". According to Chiun (2013) the comprehensive conception to this social work product has beginnings in modern industrial societies:

It is a product of modern life in industrial societies - substituting functions of extended family and kinship system; provides affectional, developmental, socialization, rehabilitative needs; facilitating economic growthhuman resource development (e.g. by education); producing vs. consuming society resources; sustaining individuals in periods of dependency (e.g. sickness, disability, maternity, retirement, unemployment).

Chiun noted further that the historical development of social welfare as a social institution was marked by stages known as pre-industrial, agricultural, rural society industrial urban society: (post-19th century) with social welfare provision amply provided differently by family, kinship system, neighbourhood, informal support networks, religious institutions combined with a systematic provision by state/government. The people involved in the social work were variously laymen, non-professionals, unspecialized workers and later on by specialized, professionalized social welfare specialists with elaborated differentiated services. From the beginning, the basis of welfare was based upon a philosophy of normative values of mutual help, kinship or locality ties, charity, religious beliefs which largely depended upon liberal values of both universal and welfare right. At the beginning, the nature of the social service was largely remedial in nature, selective, stigmatized; safety net approach, social wage concept, etc.; institutionalized; conceived as an integral system of society, not a remedial appendage. Development of welfare state in post-war European countries-Britain as illustration (Chiun, p. 89):

- 1942 Beveridge Report paved the way for welfare reform-i.e. increasing government role in welfare provision;

- Post-war Keynesian economic theory dominated-state intervention in economy to boost demand;

- Closely related to economic, political and socio-cultural development of society.

In this historical evolution, models of welfare were classified as residual welfare-à industrial-achievement; à institutional; or free-market capitalistic, individualistic_à socialist ideals, "welfare state" or finally, residual/ institutional which all dealt with the issues of the nature charity, assistance, citizen right and defined also the basis of provision and qualification such as selective (e.g. means test, eligibility); universal entitlement; social stigma may carry stigma or no stigma Ideology, free market, individual responsibility, collectivist and state responsibility. In other words, it boils down to who has the responsibility to provide social welfare, when, how and to who. The social functions or emphasis of welfare is largely determined by philosophy and value preferences of the government, social and political situation and economic affordability, inter-related functions of services, complementary roles of services at different levels. Social welfare has four levels of functional philosophy and purposeful functions of remedial, preventive development and supportive as elaborated upon below:

1) Remedial: removing disabling conditions, regaining normal functioning; needy groups, under-privileged sector in society, minimum standard of service provision, emergency relief, ad hoc basis, remedy gross hardships and human sufferings, minimum state intervention, private and family care, alleviate abnormalities, short-term basis; also related to residual services;

2) Preventive: early prevent abnormal behaviour and conditions; creating new conditions; eliminate causes of problems, research analysis on causes for effective prevention, prevention is better than cure, screening service, early identification, systematic planning, universal services, etc.;

3) Developmental: improving situations, development of individual and society, constructive planning, social investment, awareness on social responsibility, develop potentials and new capacities, growth towards mature and responsible citizenship; 
4) Supportive: achieving objectives of other sectors in society; mutual benefits among various services and clienteles, support services, education and continuous training, community support; inter-related nature of various social policies; better effectiveness and efficiency, economy;

Social welfare has different levels of coverage, types and classifications which range from the poor and most needy to all citizens (in different socio-economic strata); from almsgiving, charity to social development in general; and from particular to general; from selective to universal. The different types and classifications defined in the context of narrow vs. broad perspectives are seen as individual, personal; fiscal; occupational; social (including all 5 systems of social services); classification by role/functions: (above): * range from "revolutionary" to "social control" role; classification by targets: elderly, youth, family, disabled, offenders, communities, women, adults. Social work could also be seen from the point of view of its targeted objectives such as the achievement of optimal income security, income redistribution in society; provision of basic need like housing, health, material needs, education, environmental quality, safety; and the guarantee of social rights and social functioning. The philosophical characteristics of social welfare programmes are the attributes of its conceptual clarifications such as the following:

1) Serve community interests-derived from community need assessment, service design to satisfy such needs;

2) Value-based - e.g. human rights, citizen responsibility, social justice, prosperity, stability, equity, etc.;

3) Non-market activities - not directly capital generating, not subject to purely market mechanism/dynamics (i.e. demand and supply), depends on donation, subsidy, fee charging; [but more recent theories suggest that welfare can also be operated in a "mixed market" mode];

4) Accessible to all-citizen right, efficient service delivery system, equal opportunity;

5) Accountable to public-effective public and social administration, professional code of practice.

Nevertheless, Wilensky \& Lebeaux (2013: p. 121) gave the five features of social welfare as "organization-delivered through organizations (govt \& NGOs); social sponsorship \& accountability—service providers answerable to funding sources (govt \& donations), to provide quality service; non-profit motive [though sometimes feecharging; functional generalization: to meet different aspects of society need; direct focus on human consumption (e.g. housing, medical service).

\section{Social Welfare Development and Socio-Economic/Political Development}

In the field of social welfare, social philosophy has collaborated with social work research to establish three major practical dimensions of economic, political and social domains which account for its dynamics, principles and knowledge systems. They need further elaboration.

\subsection{Economic Domain}

The economic domain is made up of the following conceptual features (Chiun: p. 45):

The mode of production-relation of production (mode of ownership of means of production) - e.g. agrarian society vs. industrial society will have different modes of welfare (see above); economic structure: proportions of the various components of agriculture, industries (light vs. heavy), commerce, service, finance... etc.; ratio of public (government) and private sector in entire economy; or government's control of economy; level of productivity in society: labour productivity-quantity (population size, structure) and quality (education and skill level, orientation to work) - wealth of nation (Gross National Product GNP - a higher productivity can produce greater GDP/GNP to finance welfare; government financial policy \& situation: source of revenue-tax base, tax structure $\&$ policy; fiscal policy, balance of payment; and monetary policy - control over the economy; higher tax can finance more welfare; citizens' mode of consumption: culture, value system, family functioning; greater personal saving will reduce government's welfare burden.

\subsection{Political Domain}

The political domain is defined by the structure of society: social cleavages-conflicts (e.g. race, religion, economic situation, sex, etc.); configuration/structure of political power; more pluralistic society encourages more welfare for different sectors of people; legitimacy/origin of political authority (government formation): pluralistic competition or autocracy? For example, a government without citizens' legitimization may provide more welfare to 
appease citizens. The structure of the polity such as mutual check-and-balance among the 3 branches of authoritylegislature, executive, and judiciary? For example, a more powerful legislature may force the executive branch to provide more welfare (to appease the electors). Another determinant is the political culture such as civil society developed or authoritarianism? Are the people participatory or apathetic? For example, a more participatory citizenry may force government to provide more welfare; or the salience and coverage of government intervention: extent of government influence/penetration into citizen's living.

\subsection{Social Domain}

The population of a society, the social structure of the civil society and the culture define the content of the social dimension and domain of social welfare. These three dimensions could be elaborated upon:

Population: 1) quantity \& structure ("dependency ratio", productivity); quality (education, skill, technology, work ethic, etc.); a more productive population may produce higher GDP to finance more welfare; 2) social structure (of the civil society): family structure and functions; civic organizations (e.g. kaifong associations, kinship or locality associations, trade unions/professional associations, pressure groups, religious organizations, etc.) numbers, activity and function in society; stratification -along wealth, race, religion, sex, prestige, etc. (the 3 "P"s: property, prestige, power); 3) culture: value system, norms, moral standards, traditions; religions; political culture, civic awareness, etc.; a "self-reliant" culture may reduce demand for government welfare.

\section{Conceptual Framework for Studying Social Welfare}

Every discipline needs a conceptual framework that will facilitate the conduct of research questions, needs, challenges and need for a shift in theoretical underpinnings for scholars. In the first place, for social work there is a need to identify the need/problem of the social environment. This identification process will involve the asking of the following questions: what kind of problem is faced by the people concerned (e.g. the elderly, the children, the disabled, the women or what kind of need is derived from such kind of problem(s): e.g. the problem of inadequate jobs calls for the need for job placement, the problem of inadequate nutrition calls for the need for improvement in diet. Next in the process is to assess the degree or extent of such kind of problem and need, e.g. number of people affected, proportion in society, duration of such kind of problem and finally analyze the various possible factors leading to such problem and need: Is it caused by individual or social factors? e.g. individual inadequacy in character (e.g. being lazy?) or societal structural problems? (e.g. racial or sexual discrimination, deprivation ...?) Is it caused by single or multiple factors? Assess and weight the relative incidence of different possible factors attributing to the problem/ need. After his social problem process identification and review, the social philosopher and the social worker owes the client the moral obligation to identify the agents who/which are responsible directly/indirectly to cause the problem: Are the individuals who are suffering responsible for their own problems? Is the government responsible? Are the employers responsible? or ask if the other social systems like the family, the religious institutions, interest groups, etc. responsible? The sequence of conceptual ambience must be concluded in a practically sustainable sense that will lead effectively to relief for the vulnerable. Otherwise the social work process will not lead to social welfare for the less priviled or the victim of social underdevelopment. This explains why the next questions-What can be done to remedy the problem or satisfy the need? What measures can be taken to improve the situation? e.g. increasing welfare ? Improve functioning of some social systems like the family, the neighborhood, the kinship system, the religious institutions, the educational system, the political system. Must be posed consistently and continually by the mind and competency of the social orker in social philosophy. The last segment has to do with the critical examination of underlying values, assumptions, beliefs, cultural norms/traditional mores that constitute the core of the principles and practice of social work either at the state, public or non-governmental organizational levels. This portrays social work as a valueladen process with a cultural context. This means that there is no how social work can be social work in abstraction with a background of the cultural ethos of the affected comunties or society. These values permeate and make sense out of the following questions: is the definition/identification of problem/need affected by some specific set of beliefs/values? Is the identification of responsible agents biased by some particular assumptions (e.g. the government should bear ultimate responsibility to provide welfare); Is the decision on choice of solutions affected by some non-rational, not well-thought considerations? (e.g. increase welfare provision by government will incur higher taxes, will the economy be affected? (Chiun: p. 9) 


\section{The State, Regulatory Framework and Levels of Policy/Implementation}

The state according to Gandhi, has no better business except to cater to the social welfare of the less privileged, the vulnerable, the weak, the physically challenged and the marginalized (Weber, 2006: p. 67). The state puts into place governance system that has a social development policy meant for the welfare of its citizens. The state welfare system changes in its regulatory environment as different systerm evolve from continent to continent. Partnership and collaboration is a common approach with different combinations of agreements ranging from government/Ngo partnership contributions and sponsorships with the state coming up with different subventions or financing options. Major options and types of plans provide different levels of analysis and planning for social welfare service provision at the state level and within the state for different stakeholders. The challenge in governance in the African state is that people do not have their contributions nor participate in social policy interventions. The issue has always been for discussion: Is there enough public participation or professional input in drafting and planning of various plans for Social welfare planning approaches? The Hong Kong example of participatory social work policy constructions are notable with their classifications by target groups: handicapped, old people, youth, family, women; by population: neighbourhoods, areas, districts, region; by social problems: drug addiction, prostitution, housing, violent crime, alcoholism; by division of labour: medical service, financial service, housing, transportation, education, welfare service. The Hong Kong Government example has been studied and documented by Chiun (46):

1) White paper: policy paper for laying down the major basic principles of the government in provision of welfare, usually published after the consultative green paper, 4 White Papers: 1965, 1973, 1979, 1991 "Social Welfare into the 1990's".

2) 5-year Plan: 5-year rolling plan of various social welfare programs, review biannually by both SWD and voluntary sector (HKCSS).

3) Program Plan: detailed plan of a particular social welfare service, e.g. personal service for youth, elderly, rehabilitation, social security, etc.

4) Financing of Social Welfare in Hong Kong - 4 major sources of funding for social welfare: 1) government (subvention); 2) donations (from overseas or local); 3) program /membership fees; 4) independent funds (e.g. Lotteries, Keswick Foundation, etc.).

The government adopts different subvention practices at different periods of time:

- Standard Cost subvention: i.e. a standard rate of subsidy is calculated according to the operating expenses (e.g. salaries for social workers, program fees) e.g. OR, FLE, NLCDP, School SW, Family Counseling, C \& Y Centre);

- Model System: provided on the basis of recognized costs of the unit;

- Discretionary grant: most NGOs; Deficiency grant: e.g. SARDA, hospitals, schools;

- E.N.D. Formula-Essential, Necessary, Desirable 3 types of services with decreasing priorities of subsidy; Category I (100\% subsidy) \& Category II (70\%);

- 1995 SWD started to consider revising subvention policy, proposed "unit grant", "funding \& service agreement"; 1998-2000 Lump Sum Grant.

A trend for NGOs to change from depending mainly on overseas funding (mainly in 1950-60s) — to rely heavily on government. subvention-will eventually change to fee charging in future [issue for discussion: Why doesn't the govt. run the service by herself when services are totally funded by the govt? Who are involved in the provision of services in Hong Kong? (directly or indirectly):

1) Government-SWD (mainly statutory services and some family service with professional social worker \& CSSA without prof. soc.wk); \& other departments (non-social-work) e.g. Municipal Councils also provide libraries, Educ. Dept., Recreation \& Sports Dept. also provides such activities; Police also organizes JPC;

2) Non-government organization (NGO) HKCSS \& other non-HKCSS member agencies, with or without professional social workers (e.g. religious \& other traditional philanthropic organizations, clansmen \& kaifong associations, etc.). Government subvention, overseas fund, Community Chest, Lotteries Fund, fund raising, other funds, fee charging from clients/service users.

From the above study we have noticed one good example of partnership of the government and non-governmental organizations (NGOs)-Chiun, 2013:

1) NGOs contributions: usually start upon private initiatives, small, innovative, pilot projects, volunteer participation, responsive to new needs, cheaper to run, watchdog role; 
2) Government contributions: manifestation of goals of equality and fraternity, legislation, control, set and uphold standard, subvention control, statutory services, monitoring of public funds, institutionalize policy and service planning, welfare state provision from "Cradle to Grave";

3) Individuals and family contributions: informal support, source of gratification, personal care, emotional dependency;

4) Community contributions: informal assistance and support from neighbors, volunteers, etc. donations (e.g. Community Chest, Tung Wah \& PoLeung Kuk fund-raising, etc.).

\section{The African Communal Experience and the Global Definition of Social Work and Social Welfare}

At this juncture the ambience of the article should disappear as the elements of contention enter into the discussion. The handle and the key is the concept of cultural competence and communal values. In the context of the two-cultural competence we have the insight drawn by Cross et al. (1989) Towards a Culturally Competent System of Care, Washington DC: CASSP Technical Assistance Center, p. 13 on Cultural Competence:

Throughout the curriculum and in programming, students receive training in cultural competence. Terry Cross' cultural competence continuum provides the foundation for this training. Cultural competence is a set of congruent behaviors, attitudes and policies that come together in a system, agency or professional to work effectively in cross-cultural situations. The word culture is used because it implies the integrated pattern of human behavior that includes thought, actions, customs, beliefs, values and institutions of racial, ethnic, religious or social group. The word competence is used because it implies have the capacity to function effectively. A culturally competent system of care acknowledges and incorporates - at all levels - the importance of culture, the assessment of cross-cultural relations, vigilance towards the dynamics that result from cultural differences, the expansion of cultural knowledge and the adaptation of services to meet culturally unique needs.

Going further, we must understand the need for such a unique cultural intervention and conception as given the complexity of the question presented here, it is unlikely that anyone could produce a thoughtful discussion around the question without recognizing that we hold several philosophies of social work. In its simplest form, there is the understanding of systems theory and person-in-environment. Beneath these concepts we find discussions about ethics and why we do what we do. But beneath the ethics, we find that we do have a philosophy of social work that is intimate and personal as well as professional. Here is where I believe we can truly identify the real philosophy, the personal philosophy that then influences our public philosophy. This is the space where we must begin to "flesh-out" our position with clarity so as to have a clearer understanding of all that rests upon it. The commentary above identifies the fact that the debate cultural and communal relevance of social serves to unpack the core concepts used in the definition and is detailed in relation to the social work profession's core mandates, principles, knowledge and practice. Three areas of core mandates, knowledge and practice have been penciled down as the areas requiring cultural relevance and would deserve further elucidation. As simplistic as it may sound, a determination of what constitutes its core mandates, the International Federation has given a much more subtiantial conceptual elucidation of what is the core mandate of social work globally:

The social work profession's core mandates include promoting social change, social development, social cohesion, and the empowerment and liberation of people. Social work is a practice profession and an academic discipline that recognizes that interconnected historical, socio-economic, cultural, spatial, political and personal factors serve as opportunities and/or barriers to human wellbeing and development. Structural barriers contribute to the perpetuation of inequalities, discrimination, exploitation and oppression. The development of critical consciousness through reflecting on structural sources of oppression and/or privilege, on the basis of criteria such as race, class, language, religion, gender, disability, culture and sexual orientation, and developing action strategies towards addressing structural and personal barriers are central to emancipatory practice where the goals are the empowerment and liberation of people. In solidarity with those who are disadvantaged, the profession strives to alleviate poverty, liberate the vulnerable and oppressed, and promote social inclusion and social cohesion. The social change mandate is based on the premise that social work intervention takes place when the current situation, be this at the level of the person, family, small group, community or society, is deemed to be in need of change and development. It is driven by the need to challenge and change those structural conditions that contribute to marginalization, social exclusion and oppression. Social change initiatives recognize the place of human agency in advancing human rights and economic, environmental, and social justice. The profession is equally committed to the maintenance of social stability, insofar as such stability is not used to marginalize, ex- 
clude or oppress any particular group of persons.

Human rights of the global citizen is about the guarantee of the worth, dignity, respect, freedom and self realization of the citizen. But human rights realization and fulfillment must be in the context of the cultural rights and communal values of the individual as a cultural citizen. What this means is that the social work must be carried out in the context of not only human rights but all the socio-political and cultural rights of the citizens. This explains why the International Federation of social workers went further to explicate upon the nexus between social work and human rights:

The overarching principles of social work are respect for the inherent worth and dignity of human beings , doing no harm, respect for diversity and upholding human rights and social justice. Advocating and upholding human rights and social justice is the motivation and justification for social work. The social work profession recognizes that human rights need to coexist alongside collective responsibility. The idea of collective responsibility highlights the reality that individual human rights can only be realized on a day-to-day basis if people take responsibility for each other and the environment, and the importance of creating reciprocal relationships within communities. Therefore a major focus of social work is to advocate for the rights of people at all levels, and to facilitate outcomes where people take responsibility for each other's wellbeing, realize and respect the interdependence among people and between people and the environment. Social work embraces first, second and third generation rights. First generation rights refer to civil and political rights such as free speech and conscience and freedom from torture and arbitrary detention; second generation to socio-economic and cultural rights that include the rights to reasonable levels of education, healthcare, and housing and minority language rights; and third generation rights focus on the natural world and the right to species biodiversity and inter-generational equity. These rights are mutually reinforcing and interdependent, and accommodate both individual and collective rights. In what may seem like a Gandhian theoretical infusion of ahimsa, the International Federation of social workers refines this sense of non-violence thus: In some instances "doing no harm" and "respect for diversity" may represent conflicting and competing values, for example where in the name of culture the rights, including the right to life, of groups such as women and homosexuals, are violated. The Global Standards for Social Work Education and Training deals with this complex issue by advocating that social workers are schooled in a basic human rights approach, with an explanatory note that reads as:

Such an approach might facilitate constructive confrontation and change where certain cultural beliefs, values and traditions violate peoples' basic human rights. As culture is socially constructed and dynamic, it is subject to deconstruction and change. Such constructive confrontation, deconstruction and change may be facilitated through a tuning into, and an understanding of particular cultural values, beliefs and traditions and via critical and reflective dialogue with members of the cultural group vis-à-vis broader human rights issues.

In terms of its disciplinary global knowledge system, the 2014 International Federation of Social Workers recognizes that:

Social work is both interdisciplinary and transdisciplinary, and draws on a wide array of scientific theories and research. "Science" is understood in this context in its most basic meaning as "knowledge". Social work draws on its own constantly developing theoretical foundation and research, as well as theories from other human sciences, including but not limited to community development, social pedagogy, administration, anthropology, ecology, economics, education, management, nursing, psychiatry, psychology, public health, and sociology. The uniqueness of social work research and theories is that they are applied and emancipatory. Much of social work research and theory is co-constructed with service users in an interactive, dialogic process and therefore informed by specific practice environments. This proposed definition acknowledges that social work is informed not only by specific practice environments and Western theories, but also by indigenous knowledge. Part of the legacy of colonialism is that Western theories and knowledge have been exclusively valorised, and indigenous knowledge have been devalued, discounted, and hegemonised by Western theories and knowledge. The proposed definition attempts to halt and reverse that process by acknowledging that Indigenous peoples in each region, country or area carry their own values, ways of knowing, ways of transmitting their knowledge, and have made invaluable contributions to science. Social work seeks to redress historic western scientific colonialism and hegemony by listening to and learning from indigenous peoples around the world. In this way social work knowledge will be co-created and informed by indigenous peoples, and more appropriately practiced not only in local environments but also internationally. Drawing on the work of the United Nations, the IFSW defines indigenous peoples as follows:

- They live within (or maintain attachments to) geographically distinct ancestral territories; 
- They tend to maintain distinct social, economic and political institutions within their territories;

- They typically aspire to remain distinct culturally, geographically and institutionally, rather than assimilate fully into national society;

- They self-identify as indigenous or tribal. http://ifsw.org/policies/indigenous-peoples

In terms of practice, the 2014 International Federation of Social Workers practice book notes that:

Social work's legitimacy and mandate lie in its intervention at the points where people interact with their environment. The environment includes the various social systems that people are embedded in and the natural, geographic environment, which has a profound influence on the lives of people. The participatory methodology advocated in social work is reflected in "Engages people and structures to address life challenges and enhance wellbeing." As far as possible social work supports working with rather than for people. Consistent with the social development paradigm, social workers utilize a range of skills, techniques, strategies, principles and activities at various system levels, directed at system maintenance and/or system change efforts. Social work practice spans a range of activities including various forms of therapy and counseling, group work, and community work; policy formulation and analysis; and advocacy and political interventions. From an emancipatory perspective, that this definition supports social work strategies are aimed at increasing people's hope, self-esteem and creative potential to confront and challenge oppressive power dynamics and structural sources of injustices, thus incorporating into a coherent whole the micro-macro, personal-political dimension of intervention. The holistic focus of social work is universal, but the priorities of social work practice will vary from one country to the next, and from time to time depending on historical, cultural, political and socio-economic conditions. It is the responsibility of social workers across the world to defend, enrich and realize the values and principles reflected in this definition. A social work definition can only be meaningful when social workers actively commit to its values and vision.

The century-old profession of social work has been characterized by global calls for culturally related changes along cultural competence lines. That is why it is argued that social work is about to change its position, developing from the status of a semi-profession towards maturity and full professionalization but for Júlíusdóttir \& Karlsson (2006):

For contemporary social work, the challenge is thus to reconstruct old experiences and narratives as professional integrity, visibility and power in a qualitative work through process. The clarification and rethinking of themes such as invisible loyalties, dichotomous thinking, conflictual positions, and incompatible meaning of social work research are highlighted as crucial tasks on the path to professional maturity. The increasing interest in and acknowledgement of theory and research in education and professional practice is, alongside an increased, although still ambivalent, emphasis on evidence — knowledge — or information-based practice, a sign of an epistemological change. New ways of thinking, whereby theory, practice, and research are viewed as an integrated, continuous interplay, may be defined as a paradigm-shift. This emerging paradigm shift and epistemological change in social work simultaneously implicates an identity transformation, a role shift. Kuhn (1980) introduced a new definition of the concept of paradigm in his influential work The Structure of Scientific Revolutions. The concept had previously referred to a thought pattern in a scientific discipline or other epistemological context (Merriam-Webster, 1900). Other contemporary experts on knowledge and science in relation to social development and social phenomena introduced different terms. Michel Foucault, in his writings on knowledge, power and disciplines (like social work), used epistéme (epistemology) and discourse for aspects of Kuhn's concept “paradigm" (Foucault, 1980; Chambon et al., 1999). Kuhn adopted the concept of paradigm to refer to the set of practices that define a scientific discipline at a particular point in time. He relates it to his idea of acknowledging that different research subjects or disciplines require different methods and tools to suit different tasks. This was revolutionary, as well as his discussion about the different ways in which disciplines use their knowledge. The social sciences consequently began to realize that they were contextually of another kind than the natural sciences. Social phenomena were parts of culture, values, ideologies and habits, all of which are subject to change.

According to this, each academic subject and discipline has to develop a basic understanding of its own meaning and common concepts. Jerome Bruner discusses in his book acts of meaning how meaning is "a culturally mediated phenomenon that depends upon the prior existence of a shared symbol system” (Bruner, 1990: p. 69) and that it relies on "preconditions to construe the social world in a particular way..." (Ibid: p. 73). The process of constructing meaning in any context is a response to historical circumstances. A profession's shared symbol system and co-created meaning shape its culture and common understanding (Bruner, 1990; Gergen, 2001). 
This means that a discipline has to develop its own core of common understanding of its meaning. Its level of maturity is reflected in the coherence of its paradigm and how well it is developed. According to a social constructivist view it needs to be processed through a narrative reconstruction on individual and group levels linked with social interactive processes in the educational and professional discourse (Gergen \& Gergen, 2004; Lindeman-Nelson, 2001; Júlíusdóttir, 2004). Structures and reforms or other instrumental interventions primarily imply first-order changes. Those are helpful in facilitating developmental processes. They can however never replace qualitative second-order change obtained through processes of working out (Watzlawick et al., 1974). Changing attitudes and old mentalities together with an elaboration of professional self-understanding of common meaning are indeed preconditions for successful structural changes. Some of these are examined in the following three areas of transforming dichotomous thinking into integration; clarifying the meaning of social work research and a third dimension is research methodology. These are the three tools and structures for effecting very needful changes to bring about a new workable paradigm that could make social work for the good of all cultural groups through the processes of integration. Clarification and transforming some conflicting issues such as culture which are part and parcel of the professional evolution. This is why Júlíusdóttir (2004: p. 12) makes the following observations:

Social work has developed through identification with — and been generated by — conflicts, social turbulence, inequality and conflicting interests in modern industrial society, as mentioned above. The beginning of the discipline thus has ideological, political and religious attachments to the moral ideals of philanthropy, social reform and human rights. For the modern academic discipline and profession, the conflicting and often hidden loyalties to these roots have probably created more obstacles than advantages. At the same time, the strength has doubtless been, and hopefully always will be, the emphasis on professional ethics and holistic approaches. The heart of social work, its mission and vision, and its empathetic qualities must therefore never be denied or erased. We must acknowledge, teach about and read the history.

\section{Conclusion}

A paradigm shift in social work implies moving away from conflictual positions such as those outlined above, towards a coherent, scientifically based practice, where the category of social work is recognized as being capable of both applying and producing theoretical professional knowledge. Epistemologically this reflects a second-order change in social work; a more coherent view of its meaning. Firmly based reformative endeavors such as structures, standards and declarations can serve as helpful tools for qualitative improvement of social work education. They favor the integrated science-practice perspective produced by this paradigm shift in social work. But before we are able to apply these endeavors effectively it has to be realized that (although being a goal in the European policy) they are tools no less than goals in the process of educational change (Júlíusdóttir, 2006). The thesis of this article is that a reflexive co-creational process is necessary for successful educational reform favoring a transformation of the professional role and institutional status of social work. It has been argued that self-understanding and preparedness for change needs to be worked out in a close and simultaneous process of:

- A paradigm shift and adaptation of new perspectives where dichotomous thinking and antagonism is rejected;

- Narrative reconstruction of the professional identity on the individual and collective level. A campaign like the NASW four-point program year 2004 is a case in point. Collective professional associations and joint conferences for both practitioners and researchers are another example;

- Favorable structural changes in accordance with the Bologna process.

In 1996, the Council of Europe presented a report by "The Steering Committee on Social Policy". In their work entitled the initial and further training of social workers taking into account their changing role the authors stress the overall importance of empowering social work education in a changing Europe by stating the following:

The pace of social and economic change has suddenly accelerated from a leisurely jog to a sprint. Inevitably, many of those who cannot keep up with the suddenly accelerated pace, or who are trampled down by it, end up in contact with the profession of social work. That is as it should be: because that is one of the primary reasons why this profession exists. Yet, the profession of social work is not a variety of magic; often its practitioners and those who educate them are nearly as disoriented — or even frightened - as anyone else. In fact, sometimes social workers are even more disoriented and frightened than the general public, because they experience more quickly than most the gap between social reality and the institutional and financial arrangements which society provides to deal with it (Council of Europe, 1996). These words are not less valid today, but ten years later we may add: 
A more coherent, unified profession with a strong inner core of consistency and outside professional autonomy is better equipped to act as an agent of resilience. A paradigm shift in which theory and research go hand in hand with a transformation of the professional identity opens up new possibilities of empowerment. When social workers feel entitled to acknowledgement, the profession will be capable of dealing effectively with diversity, fragmentation and challenging individual and global changes in our contemporary life.

\section{References}

Bruner, J. (1990). Acts of Meaning. London: Harvard University Press.

Chambon, A., Irving, A., \& Epstein, L. (1999). Reading Foucault for Social Work. New York: Columbia University Press.

Cross, T. L. et al. (1989). Towards a Culturally Competent System of Care. Washington DC: CASSP Technical Assistance Center.

Foucault, M. (1980). Power-Knowledge. New York: Pantheon.

Gergen, K. J. (2001). Social Construction in Context. London: Sage Publications.

Gergen, K. J., \& Gergen, M. (2004). Social Construction: Entering the Dialogue. Chagrin Falls, OH: Taos Institute Publications.

Júlíusdóttir, S. (2004). Theorizing Practice-Target and Tools in the Transformation Process. Nordic Conference for Social Work Education, SSKH Konferencerapport Not. 1/2004, 31-47.

Júlíusdóttir, S. (2006). The Emerging Paradigm Shift in Social Work-In the Context of the Current Reforms of European Social Work Education. Vol. 12, No. 2 (2014) Special Issue: Creating Capabilities for Socially Vulnerable Youth in Europe.

Júlíusdóttir, S., \& Karlsson, T. (2006). Some Indications for Professional Development in Social Work: A Study of Theoretical Orientation and Attitudes to Research among Icelandic Social Workers. European Journal of Social Work.

http://www.socwork.net/SWstandardsnortheuropev2.0(Petersson-Dottir2003).pdf .

Kuhn, T. (1980). The Structure of Scientific Revolution. Chicago, IL: Chicago University Press.

Lindeman-Nelson, H. (2001). Damaged Identities. Narrative Repair, Ithaca: Cornell University Press.

Mekada, J. G. (2013). The African-Centred Worldview: Developing a Paradigm for Social Work. British Journal of Social Work, 29, 251-267.

Merriam-Webster (1900). http://www.merriam-webster.com/info/

Watzlawick, P., Weakland, J. H., \& Fisch, R. (1974). Change: Principles of Problem Formation and Problem Solution. New York: W.W. Norton.

Weber, T. (2006). Gandhi, Gandhism and the Gandhians. Delhi: Roli Books Pvt. Ltd. 